\title{
Nurses' job satisfaction and their perceived organizational justice in Kerman University of Medical Sciences: an evaluation for the Iranian health system transformation plan
}

\author{
Negahban T, $\mathrm{PhD}^{1}$, Ansari Jaberi A, $\mathrm{MSc}^{2}$, Manssouri $\mathrm{H}, \mathrm{BSc}^{3^{*}}$ \\ 1- Facully Member, Dept. of Community Health Nursing, School of Nursing and Midwifery, Social Determinants of Health \\ Research Center, Rafsanjan University of Medical Science, Rafsanjan, Iran. 2- Facully Member, Dept. of Psychiatric and \\ Mental Health Nursing, School of Nursing and Midwifery, Social Determinants of Health Research Center, Rafsanjan \\ University of Medical Science, Rafsanjan, Iran. 3-MSc Student in Medical Surgical Nursing, School of Nursing and \\ Midwifery, Rafsanjan University of Medical Science, Rafsanjan, Iran.
}

Abstract

Received: February 2017, Accepted: May 2017

Background: Nurses' job satisfaction is a determining factor in providing high quality and safe care services and obtaining patient satisfaction. It seems that with the implementation of the Transformation Plan for the Iranian Health System and due to changes in various factors such as professional, individual, and organizational circumstances, nurses' perceived organizational justice, and as a result, their job satisfaction has changed. Therefore, the present study was conducted with the aim to determine nurses' perception of organizational justice and job satisfaction in the context of the Transformation Plan for the Iranian Health System.

Materials and Methods: In this descriptive study, the job satisfaction and perception of organizational justice of 345 nurses in hospitals affiliated with Kerman University of Medical Sciences, Iran, were assessed in the first half of 2016. The subjects were selected through stratified random sampling. The data collection tools consisted of the Perceived Organizational Justice Scale (Niehoff and Moorman) and Mueller/McCloskey Nurse Job Satisfaction Scale (MMSS). Data were analyzed using descriptive statistical tests, Pearson correlation, and multiple linear regression in SPSS software and with the consideration of the significance level of 0.05 .

Results: Mean score of nurses' perceived organization justice and job satisfaction were $50.580 \pm$ 12.93 and $76.000 \pm 20.34$, respectively. A positive and significant correlation was observed between perceived organizational justice and job satisfaction of nurses $(\mathrm{r}=0.635 ; \mathrm{P}=0.001)$. Based on the results of this study, nurses' perceived organizational justice can significantly predict their job satisfaction up to $39.3 \%$.

Conclusion: The rate of perception of organizational justice is a predictive factor of nurses' job satisfaction. Therefore, in the context of the Transformation Plan for the Iranian Health System, the policymakers' consideration of factors effective on the establishment of organizational justice, and as result, improvement of nurses' job satisfaction seems necessary.

Keywords: Job Satisfaction, Nurses, Iran

\section{Introduction}

Today, due to the grave effect of nurses' job satisfaction on the performance of the health care system, this concept has become an important issue in the health industry. The high rate of nurses' satisfaction is an important factor in guaranteeing the provision of high quality and safe care services and has been recognized as the barrier to them leaving their profession $(1,2)$. The shortage of competent, well trained, and experienced nurses is a fundamental and important problem in health care systems around the world, especially underdeveloped and developing countries (3).

\footnotetext{
* Corresponding author: Hossein Manssouri, School of Nursing and Midwifery, Rafsanjan University of Medical Science, Rafsanjan, Iran.

E-mail: hssn.manss@gmail.com
} 
The job satisfaction model previously used focused on individuals' feelings toward their occupation. However, it is evident that factors which result in satisfaction or dissatisfaction with a job not only rely on the nature of that job, but also on the way the expectations of the individuals from their job are met (4). Researchers have shown that job satisfaction is mainly related to the cognitive and emotional dimension; thus, it depends on employees' beliefs and emotions regarding their occupation. Therefore, discussions on job satisfaction involve the individual's feelings toward the job, interpersonal relationships in the work environment, and managers' method of impacting employees (5). In a previous content analysis study, in addition to the 3 characteristics of autonomy, interpersonal relationships, and patient care, leadership method and organizational policies were also reported as important factors in nurses' job satisfaction (6).

Evidently, the chief goal of managers of organizations is having satisfied employees and the goal of each employee is to find a job which is suited to their interests and abilities, results in their success, and is an opportunity for their promotion. Researches have shown that satisfied employees want to be creative and are more committed to the organization and the employer $(7,8)$. In the nursing profession, scientific reports suggest that nurses who seem satisfied with their occupation have higher physical, mental, and emotional capabilities and show greater effort toward accomplishing their responsibilities, and thus, the promotion of the quality of the provided care (9). Therefore, the health care services provided by them result in high patient satisfaction (10).

Many factors can predict the level of job satisfaction among nurses, such as organizational environment (11), the quality of relationships with colleagues and managers $(12,13)$, income level, working hours (14), occupational promotion and safety processes (15), and professional effectiveness (16). Some studies on Iranian nurses have shown that unsuitable work conditions, including personnel shortage, high work load, unspecified job description, lack of equipment, and limited clinical practice, conflict with doctors, administrative issues and lack of supportive working conditions (17), and low perceived organizational justice (18), result in job dissatisfaction.

Perceived organizational justice illustrates personnel's perception of fairness in organizational behavior toward them which includes the 3 components of distributive, procedural, and interactional justice (19). In an organization, in which justice is established, the efforts of the personnel for reaching their goals will not be futile. On the other hand, the clear perception of an unjust result by personnel will impact their feelings, understanding, and ultimately their behavior (20). Organizational justice has a relationship with individuals' emotional reactions. Decreased perceived organizational justice has an important role in personnel's health; it will result in increased risk of metal tensions (21), numerous absences and displacements (22), and psychiatric disorders such as aggression in the workplace (23). In the nursing profession, desirable perceived organizational justice provides the necessary conditions for nurses to achieve their career goals and has a positive effect on occupational enthusiasm, hope and optimism, effectiveness, and resiliency, and in general, the physiological capital of nurses (24).

In line with the implementation of the Transformation Plan for the Iranian Health System in the beginning of 2014 and due to the significant reduction in treatment costs, the number of referrals to governmental hospitals, and as a result, the rate of hospital bed occupancy increased. This occurrence without any variation in the environment of hospitals and increased manpower resulted in an increase in the work load of the health team including nurses. On the other hand, injustice and immense difference between the income of doctors and other health team members, and disregard for their role in the improvement of 
the quality of care which was the philosophy behind this plan has turned into a new challenge regarding organizational justice and job satisfaction of Iranian nurses (25).

Nurses are the largest group of the health team; therefore, the World Health Organization (WHO) has announced their performance in the health system as important due to its direct impact on the health of the society (3). On the other hand, scientific texts show that a comprehensive understanding of nurses' job satisfaction and its related factors in Iran, especially after the implementation of the Transformation Plan for the Iranian Health System, does not exist. Evidently, acquiring objective evidence in this regard, in addition to attracting and maintaining experienced nurses, will assist in the empowerment of nurses. Thus, the present study was conducted with the aim to determine the relationship between nurses' perceived organizational justice and job satisfaction in the context of the Transformation Plan for the Iranian Health System.

\section{Material and Methods}

This descriptive study was conducted on nurses in Shahid Bahonar, Afzalipour, and Shafa Hospitals which are affiliated with Kerman University of Medical Sciences, Iran, in 2016. The study population consisted of 1400 nurses and sampling was performed through stratified random sampling. Sample volume was determined as 345 subjects using the following equation and consideration of $\alpha=0.05$ and $\mathrm{P}=34 \%$ for the nurses' job satisfaction (26) and $\mathrm{d}=0.05$.

$$
\mathbf{n}=\frac{\left(\mathrm{z}_{1-\mathrm{a} / 2}\right)^{2} \cdot \mathrm{P}(1-\mathrm{P})}{\mathrm{d}^{2}}
$$

(Equation 1)

The study inclusion criteria consisted of a minimum of 12 months of work experience, a bachelor's degree or higher, and willingness to participate in the study. The exclusion criteria consisted of lack willingness to take part in the study, education level of lower than associate's degree, and work experience of less than 1 year. The data collection tools used were a demographic characteristics form (including questions on age, gender, work experience, employment status, education, and occupational position), and the Perceived Organizational Justice Scale (Niehoff and Mooman) (27) and Mueller/McCloskey Nurse Job Satisfaction Scale (MMSS) (28).

The Perceived Organizational Scale consists of 20 questions scored based on a 5-point Liker scale ranging from 1-5 (completely disagreecompletely agree). The highest and lowest possible scores of this scale are 100 and 20, respectively. This scale consists of 3 subscales of distributive justice (5 questions), interactional justice (6 questions), and procedural justice (9 questions). The possible scores of the subscales of distributive, interactional, and procedural justice are, respectively, 5-25, 6-30, and 9-45. In the study by Mohammadi et al., the validity of this scale was approved and it reliability was determined as 0.91 using Cronbach's alpha (29).

The MMSS consists of 31 items scored based on a 5-point Likert scale ranging from 1-5 (completely dissatisfied-completely satisfied) (28). This scale was used after writing and gaining the permission of its authors. Since this scale was used for the first time in Iran in this study, the original version of the questionnaire was separately translated into Persian by 3 professors fluent in English using the forward-backward method. The final Persian version was reviewed by one of the professors. The validity of this tool was evaluated and approved by 10 specialists (clinical nurses, faculty members in nursing, and nursing managers). The reliability coefficient of the MMSS was determined at 0.93 using Cronbach's alpha. The MMSS consists of the subscales of satisfaction with external rewards and balance between work and family (each with 3 items and total scores of 3-15), satisfaction with work schedule (6 items and total score of 6-30), satisfaction with colleagues (2 items and total score of 2-10), 
and satisfaction with interaction opportunities, professional opportunities, and rewards and acknowledgment (each 4 items and total score of 4-20), and satisfaction with control and accountability (5 items and total score of 525).

The researchers began the collection of data after obtaining approval and an introduction letter from the research council of Rafsanjan University of Medical Sciences, Iran, (ethical code: IR.IR.rums.REC.1394.232) and coordinating with the Research Deputy of Kerman University of Medical Sciences and its affiliated hospitals. The number of subjects from each hospital and each of their wards was determined in proportion to the population of nurses in each hospital affiliated to Kerman University of Medical Sciences, and then, subjects were randomly selected from each ward. The random table of numbers was used for sampling and sampling was conducted in morning, evening, and night shifts. The questionnaires were completed through selfreport method. The participants entered the study voluntarily and verbal consent was obtained from each subject. The participants were assured of the confidentiality of their information and that their names will not be recorded. Data were analyzed using descriptive statistical tests, Pearson correlation coefficient, and multiple linear regression in SPSS software (version 16, SPSS Inc., Chicago, IL, USA).

\section{Results}

Among the 346 participants, 299 (86.4\%) were women, and 116 (33.5\%), 107 (30.9\%), and 64 $(18.5 \%)$ were, respectively, official, contract, and contractual employees and the rest were employed as part of the Supplying Human Resources Plan. Approximately 328 (94.8\%) individuals had a bachelor's degree and the rest had master's degrees. The mean age of the subjects was $34.66 \pm 7.46$ years with a minimum and maximum of 22 years of age and 53 years of age, respectively. Their mean work experience was $10.38 \pm 7.59$ years with a minimum and maximum of 1 year and 28 years, respectively. The mean total score of perceived organizational justice was $50.58 \pm$ 12.93 with a minimum score of 19.05 and a maximum score of 88.25. The lowest and highest scores were obtained in the subscales of distributive (10.32 \pm 3.71$)$ and interactional justice $(24.51 \pm 7.34)$, respectively. The mean score obtained in the subscale of procedural justice was $15.73 \pm 4.65$.

The mean MMSS score of the subjects was $76.00 \pm 20.34$. The highest mean scores obtained were related to the subscales of satisfaction with interaction opportunities $(2.79 \pm 0.87)$ and rewards and acknowledgment $(2.70 \pm 0.83)$. The lowest mean scores were obtained in the subscales of external rewards (2.03 \pm 0.89$)$ and professional opportunities $(2.18 \pm 0.85)$.

Before performing correlation tests, the normality of the distribution of data was assessed. Based on the results obtained, the total scores of job satisfaction and perceived organizational justice, and the scores of the subscales of satisfaction with work schedule and procedural and interactional justice had normal distribution (Kolmogorov-Smirnov test: $\mathrm{P}>0.05$ ).

The results of Spearman's correlation coefficient presented in table 1 show that nurses' job satisfaction had a direct and statistically significant relationship with their perceived organizational justice (Pearson correlation coefficient: $\mathrm{P}=0.001, \mathrm{r}_{\mathrm{s}}=0.635$ ); with increase in organizational justice score, the job satisfaction score also increased. All subscales of job satisfaction, except interaction opportunities, had a direct and statistically significant relationship with organizational justice and its subscales (interactional, procedural, and distributive justice) (Table 1). 
Table 1: The relationship between perceived organizational justice and job satisfaction of nurses in hospitals affiliated with Kerman University of Medical Sciences, Iran, in 2016

\begin{tabular}{|c|c|c|c|c|}
\hline Variable & $\begin{array}{l}\text { Distributive } \\
\text { justice }\end{array}$ & $\begin{array}{l}\text { Procedural } \\
\text { justice }\end{array}$ & $\begin{array}{c}\text { Interactional } \\
\text { justice }\end{array}$ & $\begin{array}{c}\text { Total organizational } \\
\text { justice }\end{array}$ \\
\hline Job satisfaction & $r_{s}=0.615^{*}$ & $r_{s}=0.502 *$ & $\mathrm{r}_{\mathrm{s}}=0.575^{*}$ & $r_{s}=0.635^{*}$ \\
\hline External reward & $\mathrm{r}_{\mathrm{s}}=0.478^{*}$ & $\mathrm{r}_{\mathrm{s}}=0.261^{*}$ & $\mathrm{r}_{\mathrm{s}}=0.251^{*}$ & $\mathrm{r}_{\mathrm{s}}=0.345^{*}$ \\
\hline Work schedule & $r_{s}=0.671 *$ & $\mathrm{r}_{\mathrm{s}}=0.910^{*}$ & $\mathrm{r}_{\mathrm{s}}=0.734^{*}$ & $\mathrm{r}_{\mathrm{s}}=0.888^{*}$ \\
\hline $\begin{array}{l}\text { Balance between work } \\
\text { and family }\end{array}$ & $r_{s}=0.430 *$ & $r_{s}=0.871 *$ & $r_{s}=0.792 *$ & $\mathrm{r}_{\mathrm{s}}=0.850 *$ \\
\hline Colleagues & $r_{s}=0.366^{*}$ & $r_{s}=0.676^{*}$ & $r_{s}=0.846^{*}$ & $\mathrm{r}_{\mathrm{s}}=0.809 *$ \\
\hline Interaction opportunities & $\mathrm{r}_{\mathrm{s}}=0.072$ & $\mathrm{r}_{\mathrm{s}}=0.377$ & $\mathrm{r}_{\mathrm{s}}=0.414$ & $\mathrm{r}_{\mathrm{s}}=0.450$ \\
\hline $\begin{array}{l}\text { Professional } \\
\text { opportunities }\end{array}$ & $\mathrm{r}_{\mathrm{s}}=0.475^{*}$ & $\mathrm{r}_{\mathrm{s}}=0.377 *$ & $\mathrm{r}_{\mathrm{s}}=0.421 *$ & $\mathrm{r}_{\mathrm{s}}=0.474 *$ \\
\hline $\begin{array}{c}\text { Rewards and } \\
\text { Acknowledgement }\end{array}$ & $r_{s}=0.441 *$ & $r_{s}=0.493 *$ & $r_{s}=0.544 *$ & $\mathrm{r}_{\mathrm{s}}=0.571 *$ \\
\hline $\begin{array}{c}\text { Control and } \\
\text { accountability }\end{array}$ & $r_{s}=0.515^{*}$ & $\mathrm{r}_{\mathrm{s}}=0.445^{*}$ & $\mathrm{r}_{\mathrm{s}}=0.512 *$ & $\mathrm{r}_{\mathrm{s}}=0.563 *$ \\
\hline
\end{tabular}

Pearson correlation coefficient: $\mathrm{P}=0.001$

The results of multiple correlation analysis showed that perceived organizational justice of nurses can significantly predict their job satisfaction to $39.3 \%(P=0.001)$. Based on the correlational model, for 1 point increase in perceived organizational justice score of nurses, their job satisfaction will increase up to 0.42 points (Table 2 ).

Table 2: Correlation model between job satisfaction and organizational justice in nurses in Kerman University of Medical Sciences, Iran, in 2016

\begin{tabular}{cccccc}
\hline & \multicolumn{2}{c}{ Non-standardized coefficient } & Standardized coefficient & $\begin{array}{c}\text { Statistical } \\
\text { test }\end{array}$ & P-value \\
\cline { 2 - 6 } & $\mathbf{B}$ & SD & $\boldsymbol{\beta}$ & 14.79 & 0.001 \\
\hline $\begin{array}{c}\text { Organizational } \\
\text { justice }\end{array}$ & 0.420 & 0.028 & 0.625 & & \\
\hline
\end{tabular}

Organizational justice $16.829+0.42=$ job satisfaction

\section{Discussion}

In the present study, perceived organizational justice and job satisfaction of nurses and their correlation were evaluated in the context of the Transformation Plan for the Iranian Health System in hospitals affiliated to Kerman University of Medical Sciences. A positive and significant relationship was observed between perceived organizational justice and job satisfaction in nurses in the present study. This finding was in agreement with the results of the studies by Mortazavi et al. (30), Hassani and Jodat-Kordlor (31), Khosrozadeh et al. (32), and Safi et al. (18), all of which were conducted on Iranian nurses.
In the present study, using perceived organizational justice, the job satisfaction of nurses can be predicted up to approximately $39.3 \%$. This finding was in accordance with that of the studies by Hassani and JodatKordlor (31), ZinalZadeh (19), and Lotfi (33). However, in the study by Mahony et al., which evaluated the relationship between organizational justice and job satisfaction in the staff of higher education institutions in the USA, organizational justice only predicted job satisfaction 32\% (34). Moreover, in the study by Xerri, which was performed on nurses in 3 hospitals in Australia, interactional justice only predicts job satisfaction to $15 \%$ (35). It seems that the correlation between perceived 
organizational justice and job satisfaction will differ in different societies due to difference in conditions governing the work environment.

The findings showed that all subscales of organizational justice were correlated with job satisfaction in nurses. Therefore, no difference was observed between the subscales of organizational justice in terms of their correlation with job satisfaction. Nevertheless, in the study by Mortazavi et al., only procedural justice predicted job satisfaction and other subscales of organizational justice had no role in job satisfaction (30). However, in the study by Hassani and Jodat-Kordlor, distributive and interactional justice predicted job satisfaction up to about $40 \%$ and the role of distributive justice was greater in this prediction, but procedural justice did not have a significant relationship with job satisfaction (31). Khosrozadeh et al. studied the correlation between the subscales of organizational justice and job satisfaction in nurses and found that interactional and procedural justice had a significant correlation with job satisfaction (32). However, they found no significant relationship between distributive justice and job satisfaction (32).

In all the above-mentioned studies, a significant correlation was observed between perceived organizational justice and job satisfaction in nurses, but this correlation in the subscales of organizational justice differed between the studies. It seems that this relationship is affected by different individual and organizational factors and the share of each subscale differs in this correlation. One of the most important changes in organizational factors is the Transformation Plan for the Iranian Health System which may impact nurses' perception of different dimensions of organizational justice.

Based on the results of this study, the nurses' rate of perception of justice in the organization was average. This finding was in agreement with that of the studies by Khosrozadeh et al. on the nurses in Shiraz University of Medical Sciences, Iran (32), Amerioun et al. on nurses in the armed forces in Tehran, Iran (36),
Mortazavi et al. on the nurses in Mashhad University of Medical Sciences, Iran (30), and Manzari et al. in the personnel of Kerman University of Medical Sciences (37).

Among the subscales of organizational justice, interactional justice had the highest rate and procedural and distributive justice had the lowest rates, respectively. This order was the same in the studies by Keivanara et al. (38), Sayedin et al. (39), Ghasemian and Foroutan (40), Vatankhah et al. (41), and Khosrozadeh et al. (32). This shows the presence of shared factors creating nurses' perception of justice. Therefore, interactional justice, as the illustrator of personnel's perception of supervisors' and managers' fair behavior toward them, has the highest share in the rate of nurses' perception of justice. Moreover, the perception of unfair distribution of resources and lack of proportion of nurses' input and achievement is the main factor in the sense of injustice in the hospital.

In this study, the mean score of nurses' job satisfaction was 76. Considering the tool used, the minimum and maximum possible scores of nurses' job satisfaction were 31 and 155 . In other words, the nurses' job satisfaction was $49.03 \%$ which is slightly less than the median and is at an average level. This finding was in accordance with that of the studies by Navidian et al. (42), Charkhabi et al. (43), Asghary et al. (44), Monjamed et al. (45), and Abushaikha et al. (46). Nevertheless, Jafar Jalal et al., in a study in Iran University of Medical Sciences, Iran, in 2015, found that $61 \%$ of nurses were dissatisfied with their job and only $4 \%$ were satisfied with their job (47). Furthermore, Mirzabeyghi et al. studied job satisfaction among nurses across the country in 2006 and found that $65.69 \%$ of nurses were dissatisfied with their occupation (26). These findings show that the rate of job satisfaction among nurses has had a descending trend.

The evaluation of the subscales of job satisfaction in nurses illustrated that the nurses' highest rate of satisfaction was with the dimensions of interaction opportunities and rewards and acknowledgment and their lowest 
rate of satisfaction was with external rewards and professional opportunities. Based on the classification of the tool used in this study, external rewards includes salary and benefits and shows that the most important factor in the dissatisfaction of nurses with their occupation was related to income and benefits. The studies by Monjamed et al. (45) and Dashti et al. also reported that the lowest satisfaction of nurses was related to income and benefits(48). Nasiripour et al. studied the factors effective on the job satisfaction and performance of personnel of educational hospitals in Qazvin, Iran, and reported income and benefits and occupational safety as the most important factors effective on personnel's job satisfaction (49). Bahadori et al. analyzed the Herzberg factor pattern in health and treatment organizations (50). They found that income and benefits was the main factor effective on occupational satisfaction of personnel in health sector (50). The subscale of professional opportunities also obtained a low score. In the study by Mirfarhadi et al., profession status and satisfaction with income and benefits was the most important factor in the determination of nurses' job satisfaction (51). Considering the low score of the important and most effective subscales on nurses' job satisfaction, it seems that alteration and improvement of income and benefits and provision of professional opportunities for the independence and growth of nurses in the context of the Transformation Plan for the Iranian Health System is necessary.

\section{Conclusion}

Although there are limitations to generalizing the results of this study, it can be concluded that perceived organizational justice can be predictive factor for job satisfaction among nurses. Therefore, in the Transformation Plan for the Iranian Health System, the consideration of factors effective on establishing organizational justice, and thus, promoting nurses' job satisfaction by policymakers of the health system seems necessary.

\section{Acknowledgement}

This study was part of a master's thesis in internal-surgical nursing. The authors wish to thank all nurses in the Afzalipour, Shafa, and Shahid Bahonar Hospitals in Kerman who participates in the study.

Conflict of interest: None declared.

\section{References}

1. Aiken LH, Clarke SP, Sloane DM, Sochalski JA, Busse R, Clarke H, et al. Nurses' reports on hospital care in five countries. Health Aff (Millwood) 2001; 20(3):43-53.

2. Biegger A, De Geest S, Schubert M, Ausserhofer D. The 'magnetic forces' of Swiss acute care hospitals: A secondary data analysis on nurses'job satisfaction and their intention to leave their current job. Nursing Plus Open. 2016; 2:15-20.

3. Wong FK, Liu H, Wang H, Anderson D, Seib C, Molasiotis A. Global nursing issues and development: analysis of world health organization documents. J Nurs Scholarsh 2015; 47(6):574-83.

4. Lu H, Barriball KL, Zhang X, While AE. Job satisfaction among hospital nurses revisited: a systematic review. Int J Nurs Stud 2012; 49(8):1017-38.

5. Hülsheger UR, Alberts HJ, Feinholdt A, Lang JW. Benefits of mindfulness at work: the role of mindfulness in emotion regulation, emotional exhaustion, and job satisfaction. $\mathbf{J}$ Appl Psychol 2013; 98(2):310-25.

6. Castaneda GA, Scanlan JM. Job satisfaction in nursing: a concept analysis. Nurs Forum 2014; 49(2):130-8.

7. Yousef DA. Organizational commitment, job satisfaction and attitudes toward organizational change: a study in the local government. International Journal of Public Administration 2017; 40(1):77-88.

8. Tzeng HM. The influence of nurses' working motivation and job satisfaction on intention to quit: an empirical investigation in Taiwan. Int J Nurs Stud 2002; 39(8):867-78.

9. Risman KL, Erickson RJ, Diefendorff JM. The impact of person-organization fit on nurse job satisfaction and patient care quality. Appl Nurs Res 2016; 31:121-5. 
10. Boev C. The relationship between nurses' perception of work environment and patient satisfaction in adult critical care. J Nurs Scholarsh 2012; 44(4):368-75.

11. Goetz K, Hasse P, Campbell SM, Berger S, Dörfer CE, Hahn K, et al. Evaluation of job satisfaction and working atmosphere of dental nurses in Germany. Community Dent Oral Epidemiol 2016; 44(1):24-31.

12. Lorber M, Skela Savič B. Job satisfaction of nurses and identifying factors of job satisfaction in Slovenian hospitals. Croat Med J 2012; 53(3):263-70.

13. Zhang L, Huang L, Liu M, Yan H, Li X. Nurse-physician collaboration impacts job satisfaction and turnover among nurses: a hospital-based cross-sectional study in Beijing. Int J Nurs Pract 2016; 22(3):284-90.

14. Ibrahim NK, Alzahrani NA, Batwie AA, Abushal RA, Almogati GG, Sattam MA, et al. Quality of life, job satisfaction and their related factors among nurses working in king Abdulaziz University Hospital, Jeddah, Saudi Arabia. Contemp Nurse 2016; 52(4):486-98.

15. Schwendimann R, Dhaini S, Ausserhofer D, Engberg S, Zúñiga F. Factors associated with high job satisfaction among care workers in Swiss nursing homes-a cross sectional survey study. BMC Nurs 2016; 15:37.

16. Chamberlain SA, Hoben $M$, Squires JE, Estabrooks CA. Individual and organizational predictors of health care aide job satisfaction in long term care. BMC Health Serv Res 2016; 16(1):577.

17. Bagheri Sh, Kousha A, Janati A. Factors affecting nurses' job satisfaction: a systematic survey. Health System Research Journal 2012; 15(2):130-9.

18. Safi MH, Mohamadi F, Arshi Sh. The relationship between perceived organizational justice and organizational commitment with job satisfaction in employees of Northern Tehran Health Care Center. Community Health 2015; 2(3):172-81.

19. Zainalipour H, Sheikhi Fini AA, Mirkamali SM. A study of relationship between organizational justice and job satisfaction among teachers in Bandar Abbas middle school. Procedia Soc Behav Sci 2010; 5:198690.

20. Conlon DE, Meyer ChJ, Nowakowski JM. How does organizational justice affect performance, withdrawal, and counterproductive behavior? In: Greenberg J, Colquitt JA, editors. Handbook of organizational justice. Mahwah, NJ, United States: Lawrence Erlbaum Associates; 2005. P.301-27.
21. Elovainio M, Kivimäki $M$, Vahtera J. Organizational justice: evidence of a new psychosocial predictor of health. Am J Public Health 2002; 92(1):105-8.

22. Khan K, Abbas M, Gul A, Raja U. Organizational justice and job outcomes: moderating role of Islamic Work Ethic. J Bus Ethics 2015; 126(2):235-46.

23. Wood S, Braeken J, Niven K. Discrimination and well-being in organizations: testing the differential power and organizational justice theories of workplace aggression. J Bus Ethics 2013; 115(3):617-34.

24. Elovainio M, Heponiemi T, Sinervo $T$, Magnavita N. Organizational justice and health; review of evidence. G Ital Med Lav Ergon 2010; 32(3 Suppl B):B5-9.

25. Hashemi B, Baratloo AR, Forouzafar MM, Motamedi M, Tarkhorani MR. Patient satisfaction before and after executing health sector evolution plan. Iranian Journal of Emergency Medicine 2015; 2(3):127-33.

26. Mirzabeigi Gh, Salemi S, Sanjari M, Shirazi F, Heidari Sh, Maleki S. Job satisfaction among Iranian nurses. Journal of hayat 2009; 15(1):49-59.

27. Niehoff BP, Moorman RH. Justice as a mediator of the relationship between methods of monitoring and organizational citizenship behavior. Acad Manage J 1993; 36(3):527-56.

28. Mueller CW, McCloskey JC. Nurses' job satisfaction: a proposed measure. Nurs Res 1990; 39(2):113-7.

29. Mohamadi M, Mirzaei M, Bahrami MA, Mohamadzadeh M. Relationship between organizational justice and organizational commitment among the employees of the health center of Yazd. Journal of Healthcare Management 2014; 5(2):35-42.

30. Mortazavi S, Kargozar N. Study of the relationship between organizational justice, job satisfaction, and affective commitment on customer oriented behavior of nurses of Imam Reza hospital, Mashhad, Iran. Journal of Zanjan University of Medical Sciences \& Health Services 2012; 20(80):84-97.

31. Hasani M, Joudatkordlar L. The study of relationship between perception of organizational justice with turnover intention, job satisfaction and organizational citizenship behavior of medical staff of Urmia Imam Reza hospital. Journal of Nursing and Midwifery Urmia University of Medical Sciences 2010; 10(3):340-52.

32. KHosrozadeh M, Hosseini MA, Kashaninia Z, Sedghi Goyaghaj N, Amini M. The correlation between organizational justice and job 
satisfaction among nurses. Journal of Health Promotion Management 2016; 5(2):10-9.

33. Lotfi MH, Shirazi Pour MS. The relationship between organizational justice and job satisfaction among the employees of Tehran Payame Noor University. Procedia Soc Behav Sci 2013; 93:2073-9.

34. Mahony D, Fitzgerald Sh, Crawford F, Hnat HB. Organizational justice perceptions and their relationship to organizational commitment, job satisfaction, and turnover intention. Journal of Higher Education Management 2015; 30(1):13-26.

35. Xerri MJ. Emamining the relationship between organizational justice, job satisfaction and the innovative behaviour of nursing employees. International Journal of Innovation Management 2014; 18(1):1450004.

36. Ameriuon A, Jabbarzade Balkanlou M, Tofighi Sh, Sepandi M, Ghanjal A. Study the relationship between organizational justice and responsibility dimensions in selected hospitals of the armed forces. Journal of Nurse and Physician Within War 2014; 2(2):23-9.

37. Manzari Tavakoli A, Rajabi M. The relationship between organizational justice perception and job satisfaction: a study onemployees of Kerman University of Medical Sciences. Journal of Health and Development 2013; 2(1):22-32.

38. Keyvanar M, Shahpouri S, Oreyzi HR. Relationship among organizational justice, work engagement and positive organizational behavior of nurses via mediation of their personal career goals. Iran Journal of Nursing 2014; 27(88):22-33.

39. Seyedin SH, Ahadi Nejad B, Tourani S, Rajabifard F. The relationship between employees' perception of organizational justice and their productivity in selected educational hospitals at Iran university of medical sciences: 2011. Bioethics Journal (Quarterly). 2014; 4(13):97-116.

40. Ghasemyani Sh, Pourreza A, Forotan S. Determining the relationship between organizational justice and organizational commitment among employees of Shariati and Vali Asr hospital (as) in the year 2011. Journal of Hospital 2014; 13(3):51-8.

41. Vatankhah S, Yegane S, Nasiri T, Shams L, Atighechian G, Vazirinasab H. The relation between organizational justice and organizational citizenship behavior in hospitals of Tehran University of Medical Sciences. Journal of Payavard Salamat 2014; 7(6):54455 .
42. Navidian A, Saber S, Rezvani Amin M, Kianian T. Correlation of quality of work life and job satisfaction in nurses of Kerman University of Medical Sciences. Journal of Health Promotion Management 2014; 3(2):715.

43. Charkhabi M, Alimohammadi S, Charkhabi S. The full mediator role of job satisfaction in relationship between job characteristics and health outcomes in hospital nurses: a new conceptual model. Procedia Soc Behav Sci 2014; 159:365-9.

44. Asghari E, Khaleghdoust T, Asgari F, Khazemnezhad E. Efective factors on nurses' job satisfaction. Journal of Holistic Nursing and Midwifery 2010; 20(2):1-7.

45. Monjamed Z, Ghorbani T, Mostofian F, Oveissipour R, Nakhost Pandi S, Mahmoudi M. A nationwide study of level of job satisfaction of nursing personnel in Iran. Journal of Hayat 2005; 10(4):39-48.

46. Abushaikha L, Saca-Hazboun H. Job satisfaction and burnout among Palestinian nurses. East Mediterr Health J 2009; 15(1):190-7.

47. Jafar Jalal E, Joolaee S, Hajibabaee F, Bahrani $\mathrm{N}$. Evaluating the relationship between nurses' occupational satisfaction and patients' satisfaction with nursing service. Iranian Journal of Nursing Research 2015; 10(1):2534.

48. Dashti S, Faradmal J, Pianvayse P, Salehiniya H. Factors affecting job satisfaction among the staff of health care workers of Hamadan county in 2012. Pajouhan Scientific Journal 2014; 12(4):28-34

49. Nasiripour AA, Delgoshaie B, Kalhor R, Kiaei MZ, Shahbahrami E, Tabatabaee SS. Effective factors on staffs' job satisfaction based on herzberg theory in Qazvin teaching hospitals. Journal of Payavard Salamat 2013; 7(4):35465.

50. Bahadori M, Raadabadi M, Teymourzadeh E, Yaghoubi M. Confirmatory factor analysis of the herzberg job motivation model for workers in the military health organizations of Iran. Journal of Military Medicine 2015; 17(2):6571.

51. Mirfarhadi N, Moosavi S, Tabari R, Kazemnejad E. Predictive factors of job satisfaction among nurses in therapeuticeducational centers of Guilan University of Medical Science. Journal of Neyshabur University of Medical Sciences 2014; 2(4):2735. 